\title{
The Effects Of Single Inhaler Triple Therapy Vs Single Inhaler Dual Therapy Or Separate Triple Therapy For The Management Of Chronic Obstructive Pulmonary Disease: A Systematic Review And Meta-Analysis Of Randomized Controlled Trials [Corrigendum]
}

Lai CC, Chen CH, Lin CYH, Wang CY, Wang YH. Int $J$ Chron Obstruct Pulmon Dis. 2019;14:1539-1548.

The authors advised that they have introduced errors while preparing this article which were oversighted by all authors.

On page 1541, in Results section, Risk of moderate or severe COPD exacerbation; (rate ratio, 0.81; 95\% CI, 0.73 to $0.89, I^{2}=29 \%$; Figure 1) should be (rate ratio, $0.80 ; 95 \%$ CI, 0.71 to $0.90, I^{2}=37 \%$; Figure 1); and in Secondary outcomes, (MD, -153 ; 95\% CI, -2.23 to $-0.84, I^{2}=21 \%$; Figure 3 ) should be (MD, $-1.53 ; 95 \%$ CI, -2.23 to -0.84 , $I^{2}=21 \%$; Figure 3 ).
On page 1543 , Figure 2 should be presented as below.

On Page 1544, Discussion section, (vs LABA/LAMA, risk ratio, $0.99 ; 95 \% \mathrm{CI}, 0.44$ to $2.27, I^{2}=31 \%$; vs ICS/LABA, risk ratio, $1.00 ; 95 \% \mathrm{CI}, 0.53$ to $1.89, I^{2}=0 \%$; vs separate triple therapy, risk ratio, $0.48 ; 95 \% \mathrm{CI}, 0.18$ to $1.28, I^{2}=49 \%$; Figure S6) should be: (vs LABA/LAMA, risk ratio, 0.74; $95 \% \mathrm{CI}, 0.50$ to $1.10, I^{2}=31 \%$; vs $\mathrm{ICS} / \mathrm{LABA}$, risk ratio, $1.00 ; 95 \% \mathrm{CI}, 0.53$ to $1.89, I^{2}=0 \%$; vs separate triple therapy, risk ratio, $0.48 ; 95 \% \mathrm{CI}, 0.18$ to $1.28, I^{2}=49 \%$; Figure S6).

On page 1544, Adverse events section should be as the following:

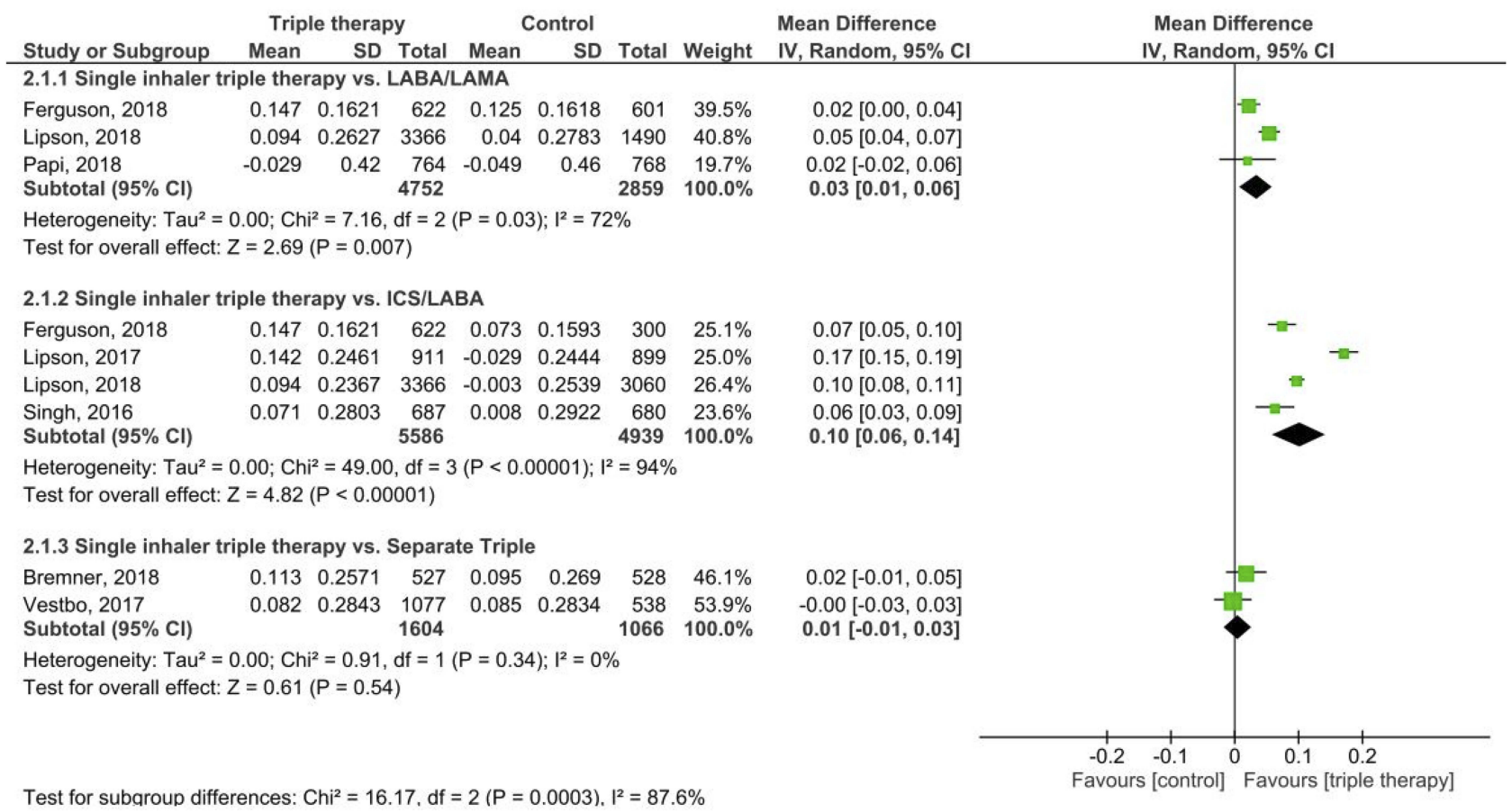


Single inhaler triple therapy was associated with a significantly higher risk of pneumonia compared with LABA/ LAMA dual therapy (risk ratio, $1.38,95 \%$ CI, 1.14 to 1.67 , $I^{2}=0 \%$ ), but no significant differences were found when it was compared with ICS/LABA dual therapy (risk ratio, 1.24, $95 \%$ CI, 0.83 to $1.85, I^{2}=48 \%$ ) or separate triple therapy (risk ratio, $0.88,95 \% \mathrm{CI}, 0.51$ to $1.52, I^{2}=25 \%$; Figure 4 ). The risk of lower respiratory tract infection (LRTI) was investigated however, no significant differences were found between sin- gle inhaler triple therapy and the three alternative treatments (vs LABA/LAMA, risk ratio, $0.90 ; 95 \%$ CI, 0.73 to 1.11 , $I^{2}=0 \%$; vs ICS/LABA, risk ratio, $1.02 ; 95 \% \mathrm{CI}, 0.85$ to 1.23 , $I^{2}=0 \%$; vs separate triple therapy, risk ratio, $0.91 ; 95 \% \mathrm{CI}$, 0.37 to $2.26, I^{2}=84 \%$; Figure S9). In addition, there were no significant differences observed between single inhaler triple therapy and the comparative treatments in regard to the risk of treatment emergent adverse events, serious adverse events, and cardiovascular events (Figure S10-S12).

\section{Publish your work in this journal}

The International Journal of COPD is an international, peer-reviewed journal of therapeutics and pharmacology focusing on concise rapid reporting of clinical studies and reviews in COPD. Special focus is given to the pathophysiological processes underlying the disease, intervention programs, patient focused education, and self management protocols. This journal is indexed on PubMed Central, MedLine and CAS. The manuscript management system is completely online and includes a very quick and fair peer-review system, which is all easy to use. Visit http://www.dovepress.com/testimonials.php to read real quotes from published authors. 